\title{
ANTIOXIDANT EFFICACY OF UNRIPE BANANA (MUSA ACUMINATA COLLA) PEEL EXTRACTS IN SUNFLOWER OIL DURING ACCELERATED STORAGE
}

\author{
Stella Sye Chee Ling ${ }^{1}$, Sui Kiat Chang², Winne Chiaw Mei Sia ${ }^{1}$, Hip Seng Yim ${ }^{1 凶}$ \\ ${ }^{1}$ Department of Food Science and Nutrition, Faculty of Applied Sciences, UCSI University \\ No. 1, Jalan Menara Gading, UCSI Heights, 56000 Kuala Lumpur, Malaysia \\ ${ }_{2}^{2}$ TÜBITAK Marmara Research Center, Food Institute \\ P.O. Box 21, 41470, Gebze-Kocaeli, Turkey
}

\begin{abstract}
Background. Sunflower oil is prone to oxidation during storage time, leading to production of toxic compounds that might affect human health. Synthetic antioxidants are used to prevent lipid oxidation. Spreading interest in the replacement of synthetic food antioxidants by natural ones has fostered research on fruit and vegetables for new antioxidants.

Material and methods. In this study, the efficacy of unripe banana peel extracts (100, 200 and 300 ppm) in stabilizing sunflower oil was tested under accelerated storage $\left(65^{\circ} \mathrm{C}\right)$ for a period of 24 days. BHA and $\alpha$-tocopherol served as comparative standards besides the control. Established parameters such as peroxide value (PV), iodine value (IV), $p$-anisidine value $(p-\mathrm{AnV})$, total oxidation value (TOTOX), thiobarbituric acid reactive substances (TBARS) and free fatty acid (FFA) content were used to assess the extent of oil deterioration.

Results. After 24 days storage at $65^{\circ} \mathrm{C}$, sunflower oil containing 200 and $300 \mathrm{ppm}$ extract of unripe banana peel showed significantly lower PV and TOTOX compared to BHA and $\alpha$-tocopherol. TBARS, $p$-AnV and FFA values of sunflower oil containing 200 and $300 \mathrm{ppm}$ of unripe banana peel extract exhibited comparable inhibitory effects with BHA. Unripe banana peel extract at 200 and 300 ppm demonstrated inhibitory effect against both primary and secondary oxidation up to 24 days under accelerated storage conditions.

Conclusions. Unripe banana peel extract may be used as a potential source of natural antioxidants in the application of food industry to suppress lipid oxidation.
\end{abstract}

Key words: unripe banana peel extract, sunflower oil, accelerated storage, antioxidants, lipid oxidation

\section{INTRODUCTION}

Dietary lipids, naturally occurring in raw food materials or added during food processing, play an important role in food nutrition and flavour. Meanwhile, lipid oxidation is a major cause of food quality deterioration, and has been a challenge for manufacturers and food scientists alike (Shahidi and Wanansundara,
2002). Consequently, lipid oxidation will give rise to the development of off-flavours and loss of essential amino acids, fat-soluble vitamins, and other bioactives in food systems. Lipids may undergo autoxidation, photo-oxidation, thermal oxidation, and enzymatic oxidation, most of which involve some type of free 
Ling, S. S. C., Chang, S. K., Sia, W. C. M., Yim, H. S. (2015). Antioxidant efficacy of unripe banana (Musa acuminata Colla) peel extracts in sunflower oil during accelerated storage. Acta Sci. Pol. Technol. Aliment., 14(4), 343-356. DOI: 10.17306/J.AFS.2015.4.34

radical or oxygen species, producing lipid hydroperoxides (Shahidi and Zhong, 2005; Shahidi and Wanansundara, 2002). Lipid hydroperoxides and some of their end products can interact with biological components, such as proteins, cell membranes and enzymes in human body, affecting vital cell functions (Shahidi and Zhong, 2005). Failure to repair damaged biological components will cause the physiological overproduction of free radicals. The scientific community has discovered that fatigue and many human illnesses are associated with free radicals (Halliwell, 2012). Hence, the consumption of antioxidants will help to reduce oxidative damage in vivo, thereby reducing the incidence of human diseases (Halliwell, 2012).

To prevent such a quality loss due to lipid oxidation, synthetic antioxidants have been widely utilized to retard lipid oxidation in various food systems. However, the uses of synthetic antioxidants have raised concerns about possible toxicity and side effects (Maqsood et al., 2013). Hence, the usage of natural antioxidants has been increasingly adopted as an effective methodology to prevent rancidity in various edible oils. Many phenolic-rich plant extracts have successfully demonstrated the retarding effect on lipid oxidation of various edible oil due to their good antioxidant capacity (Zhang et al., 2010; Dillard and German, 2000). For example, oyster mushroom, garlic, kenaf seed, pomegranate, olive, tea and Moringa oleifera extracts have been demonstrated to delay lipid peroxidation in various oils compared to synthetic antioxidants (Malheiro et al., 2013; Nyam et al., 2013; Yim et al., 2013; Pazos et al., 2005). There are some studies which demonstrated the effectiveness of fruit peel, such as rambutan (Nephelium lappaceum L.), mangosteen (Garcinia mangostana Linn.) and pomegranate peel extracts to prevent the oxidative rancidity of sunflower oil under accelerated conditions (Chong et al., 2015; Winne Sia et al., 2014; Iqbal and Bhanger, 2007). It is well known that the antioxidant capacities of fruit extracts are due to the presence of phenolic compounds (Pedraza-Chaverri et al., 2008). However, there is still lack of studies to determine the efficacy of fruit/fruit peel extracts in preventing oxidative rancidity of vegetable oil (Okonogi et al., 2007).

Banana (Musa species) is originated from the family of Musaceae and can be classified into two main species, which are Musa acuminata and Musa balbisiana (Valmayor et al., 2002). Bananas are an important food crop in the subtropics and tropics being a good source of nutrients and energy. Bananas are often categorized as 'dessert' sweet bananas, which are ripened and eaten raw, but also edible when fully ripe (Perrier et al., 2011). The peel of banana is a typical waste after consumption or disposed by banana crisp industries (Oliveira et al., 2008). Besides its flesh, banana peel contains potent antioxidant compounds. Vitamin A, vitamin $\mathrm{C}$, and carotenoids are the most abundant antioxidants in banana flesh as well as in banana peel (Arora et al., 2008; Pereira and Maraschin, 2015; US Department..., 2014). Banana peels have been shown to demonstrate higher antioxidant capacity (AC) than the pulp (Pereira and Maraschin, 2015; Oliveira et al., 2008; Someya et al., 2002). Moreover, unripe banana peels have been shown to demonstrate higher antioxidant capacity than the ripened banana peel (Pereira and Maraschin, 2015). Hence, banana peel could be one of the natural sources of antioxidant (Pereira and Maraschin, 2015; Oliveira et al., 2008).

Sunflower oil contains about $59 \%$ of polyunsaturated fatty acids (PUFA; linoleic acid) and 30\% of monounsaturated fatty acids (MUFA; oleic acid; Normand et al., 2001). Due to its high PUFA content, sunflower oil is highly susceptible to lipid oxidation (Aladedunye and Przybylski, 2009; Normand et al., 2001). Hence, sunflower oil has been used as a model to investigate the ability of various plant extracts in preventing its peroxidation, as previously reported (Winnie Sia et al., 2014; Nyam et al., 2013). Ripe banana peel water-extract have been shown to suppress the auto-oxidation of linoleic acid by $65-70 \%$ after 5-day incubation in an emulsion system by determining its peroxide value and thiobarbituric acid reactivity (Kanazawa and Sakakibara, 2000). However, no study has ever been conducted on the efficacy of unripe banana peel in preventing lipid peroxidation under accelerated storage conditions. Hence, this study aims to determine the effectiveness of unripe banana peel extract in preventing sunflower oil rancidity under 24 days of accelerated storage conditions. Crude unripe banana peel extract was standardized to the levels of $100,200,300 \mathrm{ppm}$ and added to each sunflower oil sample. Sunflower oil samples that are stabilised with $\alpha$-tocopherol (200 ppm) and BHA (200 ppm) were 
Ling, S. S. C., Chang, S. K., Sia, W. C. M., Yim, H. S. (2015). Antioxidant efficacy of unripe banana (Musa acuminata Colla) peel extracts in sunflower oil during accelerated storage. Acta Sci. Pol. Technol. Aliment., 14(4), 343-356. DOI: 10.17306/J.AFS.2015.4.34

used as standard, whereas, the control sunflower oil sample was without additives. Oxidative changes were monitored by the peroxide value, $p$-anisidine value, iodine value, 2-thiobarbituric acid reactive substances and free fatty acid value, as well as the calculated total oxidation value.

\section{METHODOLOGY}

\section{Materials and reagents}

Refined, bleached and deodorized (RBD) sunflower oil without additives and antioxidants was purchased from MOI Foods Malaysia Pte. Ltd., Selangor, Malaysia. The unripe tropical fruit, banana (Musa acuminata Colla) was purchased from a local wet market in Kuala Lumpur, Malaysia. The fruits were cleaned and inspected to remove damaged or diseased fruits. Following this, the peel was separated from its edible pulp. The unripe banana peel was then washed, air dried followed by drying in the oven at $40^{\circ} \mathrm{C}$ for $24 \mathrm{~h}$ and ground to powder using a food processor after filter through a $1.0 \mathrm{~mm}$ sieve using a miller. The unripe banana peel powder was vacuum packaged into a sterile sample bag by using a vacuum packaging machine (DZQ 400/500, Zhejiang, China) prior to analysis. All chemicals and reagents used were of analytical grade from Merck (Merck KGaA, Darmstadt, Germany). BHA and $\alpha$-tocopherol were purchased from SigmaAldrich (St. Louis, MO, USA). Water used throughout the study was of ELGA Lab Water (Micromeg, UK) quality.

\section{Extraction}

Oven-dried unripe banana peel powder $(50 \mathrm{~g})$ was dissolved in $500 \mathrm{ml}$ ethanol-distilled water $(9: 1, \mathrm{v} / \mathrm{v})$ and subjected to agitation at $150 \mathrm{rpm}$ at room temperature on a shaker for $120 \mathrm{~min}$ (Green Seriker, Korea). Subsequently, the mixture was centrifuged at $4000 \mathrm{rpm}$ for 10 min (Universal 320R, Hettich Zentrifugen, MA, USA) and supernatant was filtered through a Whatman No. 1 filter paper. The residue was re-extracted twice where both extracts were combined and concentrated in a rotary evaporator (Rotavapor R-200, Buchi, Switzerland) at $35^{\circ} \mathrm{C}$. Crude extracts obtained where then freeze-dried (ALPHA 1-4LD Plus, Christ, Germany), vacuum packaged and stored under refrigeration until further analyses.

\section{Preparation of sample extract for determination of oxidative stability}

Sunflower oil was stored under accelerated conditions at $65^{\circ} \mathrm{C}$ over a period of 24 days according to method described (Iqbal and Bhanger, 2007) with slight modifications according to Chong et al. (2015). The accelerated storage condition involves placing a known volume of oil sample in a forced-draft oven at $65^{\circ} \mathrm{C}$, where each day under such oven storage test at $65^{\circ} \mathrm{C}$ is equivalent to one month of the storage at ambient temperature (Chong et al., 2015; Yim et al., 2013). First, crude extracts of unripe banana peel were dissolved with $150 \mu \mathrm{L}$ absolute ethanol and added into $250 \mathrm{~mL}$ pre-heated sunflower oil (at $50^{\circ} \mathrm{C}$ for $3 \mathrm{~h}$ ) at concentrations of 100 and $200 \mathrm{ppm}$. All the samples were prepared separately for different day of storage time. Samples were not drawn from the sample bottle. They were kept in the oven until till day of analysis. After that, the oil samples were placed in a water bath sonicator for $1 \mathrm{~h}$ at $60^{\circ} \mathrm{C}$ to ensure homogenous dispersion. Synthetic antioxidant (BHA) at its legal limit of $200 \mathrm{ppm}$ and $\alpha$-tocopherol (200 ppm) were used as the comparative standards. All samples $(250 \mathrm{ml})$ were placed in closed amber bottles and stored in oven at a fixed temperature of $65^{\circ} \mathrm{C}$. Control sample of sunflower oil was placed under identical condition without the addition of sample extract. Oxidative changes were monitored by the peroxide value, iodine value, $p$-anisidine value, 2-thiobarbituric acid reactive substances and free fatty acid value at 0 day and at regular intervals of 6 days for 24 days.

\section{Analysis of Peroxide Value}

Peroxide Value (PV) of all samples was measured according to the AOAC method 965.33 with slight modification (O'Keefe and Pike, 2010; Zhang et al., 2010). Sunflower oil samples ( $2.00 \mathrm{~g})$ were dissolved in $30 \mathrm{~mL}$ of acetic acid-chloroform $(3: 2 ; \mathrm{v} / \mathrm{v})$ solution. Then, $1 \mathrm{~mL}$ saturated solution of potassium iodide (KI) was added. The mixture was shaken by hand for $1 \mathrm{~min}$ and was kept in the dark for $5 \mathrm{~min}$. After addition of $75 \mathrm{~mL}$ distilled water, the mixture was titrated against $0.022 \mathrm{M}$ sodium thiosulphate $\left(\mathrm{Na}_{2} \mathrm{~S}_{2} \mathrm{O}_{3}\right)$ until the yellow colour was disappeared. Subsequently, 0.5 $\mathrm{mL}$ of starch indicator $(1 \%)$ was added where titration was continued until the blue color of the mixture disappeared. The blank was analysed under similar 
Ling, S. S. C., Chang, S. K., Sia, W. C. M., Yim, H. S. (2015). Antioxidant efficacy of unripe banana (Musa acuminata Colla) peel extracts in sunflower oil during accelerated storage. Acta Sci. Pol. Technol. Aliment., 14(4), 343-356. DOI: 10.17306/J.AFS.2015.4.34

conditions. Determination of PV of each sample was carried out in triplicates and PV $(\mathrm{mEq} / \mathrm{kg})$ was calculated according to the equation:

$\mathrm{PV}=\left[\mathrm{C} \times\left(\mathrm{V}-\mathrm{V}_{\mathrm{k}}\right) \times 12.69 \times 78.8\right] /$ sample weight $(\mathrm{g})$

where:

$\mathrm{C}$ - concentration of $\mathrm{Na}_{2} \mathrm{~S}_{2} \mathrm{O}_{3}, \mathrm{mEq} / \mathrm{kg}$,

$\mathrm{V}$ - the titer value of $\mathrm{Na}_{2} \mathrm{~S}_{2} \mathrm{O}_{3}$ for sample, $\mathrm{mL}$,

$\mathrm{V}$ - the titer value of $\mathrm{Na}_{2} \mathrm{~S}_{2} \mathrm{O}_{3}$ solution for blank, $\mathrm{mL}$.

\section{Measurement of $p$-Anisidine Value}

The $p$-anisidine value $(p-\mathrm{AnV})$ was determined according to AOCS method Cd 18-90 (O'Keefe and Pike, 2010). To begin, sunflower oil samples (2 $\mathrm{g}$ ) were first dissolved in $25 \mathrm{~mL}$ isooctane. Then, $5 \mathrm{~mL}$ aliquot of this mixture was mixed with $1 \mathrm{~mL} 0.25 \%$-anisidine in acetic acid $(\mathrm{w} / \mathrm{v})$. The mixture was shaken vigorously and kept in the dark for $10 \mathrm{~min}$, and absorbance was measured at $350 \mathrm{~nm}$ using a spectrophotometer (XTD 5, Secomam, Alés Gard, France). The blank which consists of $5 \mathrm{~mL}$ isooctane was measured under similar condition. The $p$-AnV was calculated according to the equation:

$$
p-\mathrm{AnV}=25 \times\left[\left(1.2 \mathrm{~A}_{\mathrm{s}}-\mathrm{A}_{\mathrm{b}}\right)\right] / \text { sample weight }(\mathrm{g})
$$

where:

$\mathrm{A}_{\mathrm{s}}$ - the absorbance of fat solution after reaction with the $p$-Anisidine reagent,

$\mathrm{A}_{\mathrm{b}}$ - the absorbance of blank.

\section{Determination of Total Oxidation (ТОТОХ) value}

Total oxidation (TOTOX) values of the oil samples were determined based on the obtained $\mathrm{PV}$ and $\mathrm{AV}$ values as described by (Nyam et al., 2013) using the following equation:

$$
\mathrm{TOTOX}=2 \mathrm{PV}+\mathrm{AV}
$$

\section{Analysis of lodine Value}

The iodine value (IV) in the oil samples was determined by Wijs method, as describe in the AOAC Official Method 993.20 (O'Keefe and Pike, 2010). First, sunflower oil samples $(0.2 \mathrm{~g})$ was dissolved in $15 \mathrm{~mL}$ of cyclohexane-acetic acid $(1.1 ; \mathrm{v} / \mathrm{v})$ solvent. The mixture was added with $25 \mathrm{~mL}$ Wijs solution [Iodine chloride ( $\mathrm{ICl}$ ) in acetic acid] and kept in the dark for $1 \mathrm{~h}$. Then, the mixture was added with $20 \mathrm{~mL} \mathrm{15 \%}$ $\mathrm{KI}$ solution and $150 \mathrm{~mL}$ of distilled water. The mixture was gradually titrated against $0.1 \mathrm{M} \mathrm{Na}_{2} \mathrm{~S}_{2} \mathrm{O}_{3}$ solution with continuous vigorously shaking until dark brown colour disappeared. The blank was analyzed under similar conditions. The IV was expressed as the gram of iodine absorbed per $100 \mathrm{~g}$ sample $\left(\mathrm{g} \mathrm{I}_{2} / 100 \mathrm{~g}\right)$ and was calculated using the equation:

$$
\mathrm{IV}=[(\mathrm{B}-\mathrm{S}) \times \mathrm{M} \times 12.69] / \text { sample weight }(\mathrm{g})
$$

where:

$$
\begin{aligned}
& \mathrm{B} \text { - the titration of blank, } \mathrm{mL} \text {, } \\
& \mathrm{S} \text { - the titration of test solution, } \mathrm{mL}, \\
& \mathrm{M} \text { - the molarity of } \mathrm{Na}_{2} \mathrm{~S}_{2} \mathrm{O}_{3} \text { solution, } \mathrm{mol} / \mathrm{L} \text {. }
\end{aligned}
$$

\section{Thiobarbituric Acid Reactive Substances (TBARS) Assay}

Lipid oxidation of all samples was determined by 2-thiobarbituric acid (TBA) method according to the methods of Okuda et al. (2005) with slight modifications. First, $1 \mathrm{~mL}$ of sunflower oil was mixed with $2 \mathrm{ml}$ of TBA-TCA solution containing 15\% TCA and $20 \mathrm{mM} \mathrm{TBA}(\mathrm{w} / \mathrm{v})$ in distilled water. The mixture was then vortexed and incubated in water bath $\left(95^{\circ} \mathrm{C}\right)$ for 15 min until pink colour was developed. Subsequently, samples were cooled under running tap water for $15 \mathrm{~min}$ followed by centrifuge for $15 \mathrm{~min}$ at 4500 rpm. Blank solution was prepared with $1 \mathrm{~mL}$ distilled water under similar conditions. The absorbance of the supernatant was measured at $532 \mathrm{~nm}$ using a spectrophotometer against blank solution. A standard curve of malondialdehyde (MDA) was prepared using 1,1,3,3-tetraethoxypropane (TEP) where TBARS value were expressed as $\mathrm{mg}$ of MDA equivalents per kg sample.

\section{Measurement of Free Fatty Acids (FFA)}

Free fatty acids, as oleic acid percentages in oil samples, were determined using an alkali titration method according to AOAC official method 28.032 (O'Keefe and Pike, 2010). First, oil samples (7 g) were dissolved in $50 \mathrm{~mL}$ neutralized ethanol. Then, the mixture was titrated against sodium hydroxide $(0.25 \mathrm{M})$ using phenolphthalein solution as an indicator while shaking the content mixture. The mixture was titrated until permanent faint pink colour developed and persisted for 
Ling, S. S. C., Chang, S. K., Sia, W. C. M., Yim, H. S. (2015). Antioxidant efficacy of unripe banana (Musa acuminata Colla) peel extracts in sunflower oil during accelerated storage. Acta Sci. Pol. Technol. Aliment., 14(4), 343-356. DOI: 10.17306/J.AFS.2015.4.34

more than 1 min. Percentage of free fatty acids was expressed as:

$$
\% \text { FFA }(\text { oleic acid })=\underset{\text { used }}{\text { volume }}(\mathrm{mL}) \text { of } 0.25 \mathrm{M} \mathrm{NaOH}
$$

\section{Statistical analysis}

All independent analyses were carried out in triplicates $(n=3)$ for which the results were expressed as mean \pm standard deviation. Data collected were analyzed using SPSS analytical software version 21.0 (SPSS Inc., Illinois, USA). Data were subjected to one-wayanalysis of variance (ANOVA) followed by Bonferroni's test for comparison of means as a post-hoc test. Significant levels were based on the confidence level of $95 \%(p<0.05)$.

\section{RESULTS AND DISCUSSIONS}

The resistance of lipids to oxidation is known as oxidative stability. The determination of oxidative stability using actual shelf life of oil at ambient conditions of storage requires months or years. Therefore, accelerated tests are used to evaluate the oxidative stability of oils and fats. A protocol recommended by the American Oil Chemists' Society (AOCS) states that placing a fat or oil of known volume in a forced-draft oven above ambient temperature but less than $80^{\circ} \mathrm{C}$, with $60^{\circ} \mathrm{C}$ being recommended. Such temperatures are desirable accelerated storage temperatures since the mechanism of oxidation from $60^{\circ}-65^{\circ} \mathrm{C}$ is the same as oxidation at room temperature (O'Keefe and Pike, 2010). Khan and Shahidi (2001) and Iqbal and Bhanger (2007) have demonstrated that one day of accelerated storage in Schaal oven test at $65^{\circ} \mathrm{C}$, is equivalent to one month of storage at ambient temperature. In this present research, analyses were carried out every 6 days interval. Every 6 days under accelerated storage represents half year storage at ambient temperature. A combination of methods to assess both primary and secondary oxidative changes of experimental sunflower oils during accelerated storage was carried out in this study. The quality indices of sunflower oil were quantitatively determined as well, including formation of primary and secondary oxidation products, losses of unsaturated fatty acids and hydrolysis of fatty acids. Besides, the protective effects of those supplemented antioxidants were compared with those supplemented with unripe banana peel in preventing lipid peroxidation of sunflower oil (SFO). The abbreviations of SFO supplemented with 100, 200 and $300 \mathrm{ppm}$ of unripe banana peel extracts used for the following sections are SFO-100, SFO-200 and SFO-300, respectively.

\section{Peroxide Value}

The degree of primary oxidation of SFO was determined by measuring PV in the presence and absence of antioxidants at $65^{\circ} \mathrm{C}$ for 24 days. As shown in Figure 1, the PV of all the treated samples increased with time. Peroxide value (PV) is a measurement of the concentration of hydroperoxides and peroxides that are produced in the initial stages of lipid oxidation, represents primary reaction products. It is determined based by their ability to liberate iodine from potassium iodide (Nor et al., 2008). The PVs of the samples were in the range of $41.12-69.00 \mathrm{mEq} / \mathrm{kg}$, while it was 41.12 $\mathrm{mEq} / \mathrm{kg}$ and $41.92 \mathrm{mEq} / \mathrm{kg}$ for BHA and $\alpha$-tocopherol stabilized samples, respectively, after accelerated storage up to 24 days. Highest PV was observed for SFO-100 followed by control, SFO-200, SFO-300, SFO supplemented with $\alpha$-tocopherol (SFO-TOCO) and SFO supplemented with BHA (SFO-BHA), respectively, at all stages (Fig. 1). PVs of SFO-200 and SFO-300 were significantly lower $(p<0.05)$ than the control on $12^{\text {th }}$ and $18^{\text {th }}$ day, respectively, and almost as low as of SFO-BHA and SFO-TOCO on the $24^{\text {th }}$ day. However, there was significant difference $(p<0.05)$ between the PVs of SFO-BHA and SFO-TOCO with SFO-200 and SFO-300 on $24^{\text {th }}$ day (Fig. 1). Hence, it can be said that the unripe banana peel extracts added to sunflower oil can work as effective as the added BHA and $\alpha$-tocopherol. However, as compared to the control and SFO-100, the PVs of SFO-200 and SFO-300 were significantly lower $(p<0.05)$, which may indicate good antioxidant capacity due to higher concentrations of the unripe banana peel extract (Fig. 1).

\section{p-Anisidine Value}

The $p$-Anisidine Value $(p-A n V)$ is the measure of the secondary lipid oxidation product produced when the hydroperoxide decomposes to carbonyl, aldehydes, carboxylic acids and ketones. This is the stage that leads to the rancid flavor of the oil (O'Keefe and 


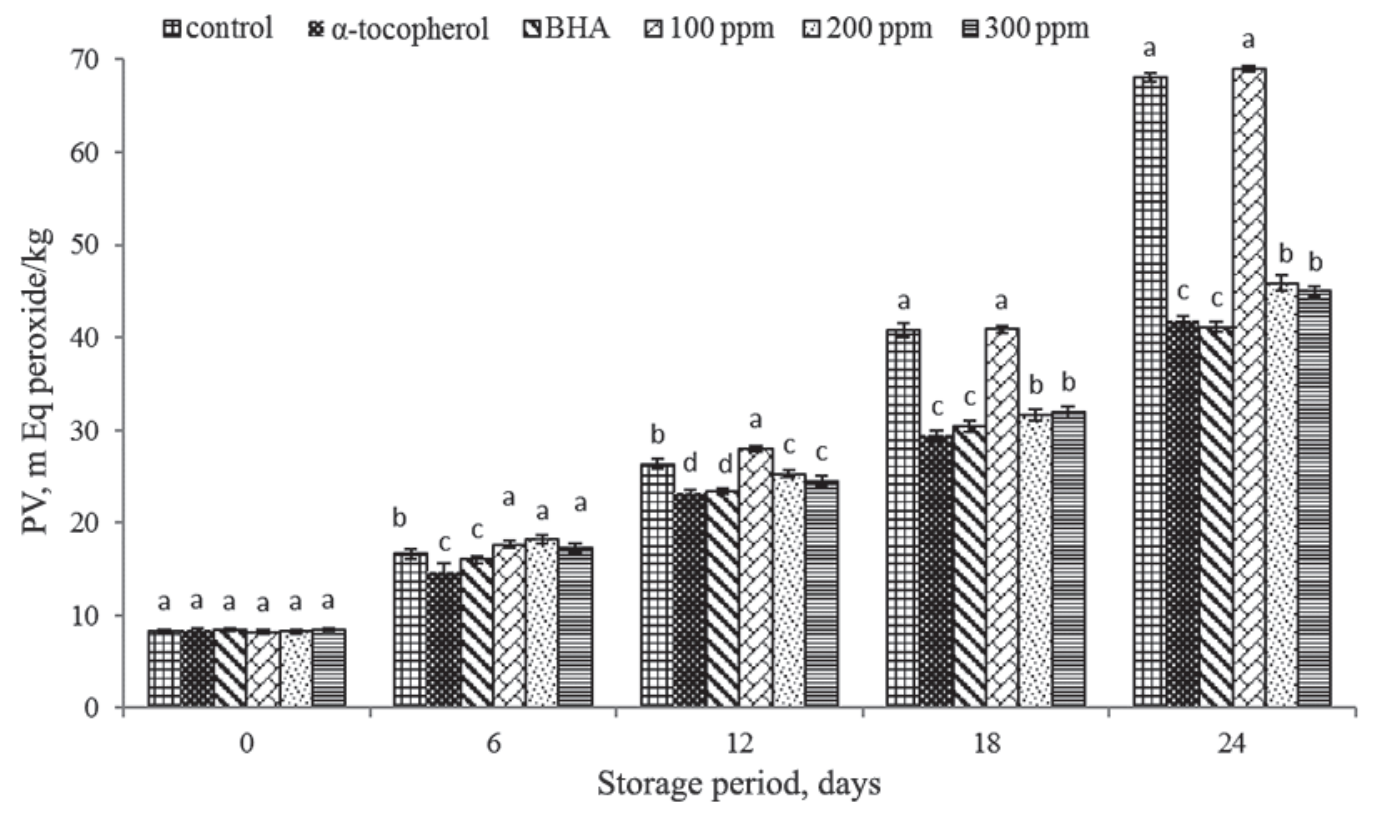

Fig. 1. Peroxide value (PV) of sunflower oil supplemented with unripe banana peel extracts, BHA and $\alpha$-tocopherol under accelerated storage at $65^{\circ} \mathrm{C}$ for 24 days. Different letters within each storage period denote that they are significantly different $(p<0.05)$

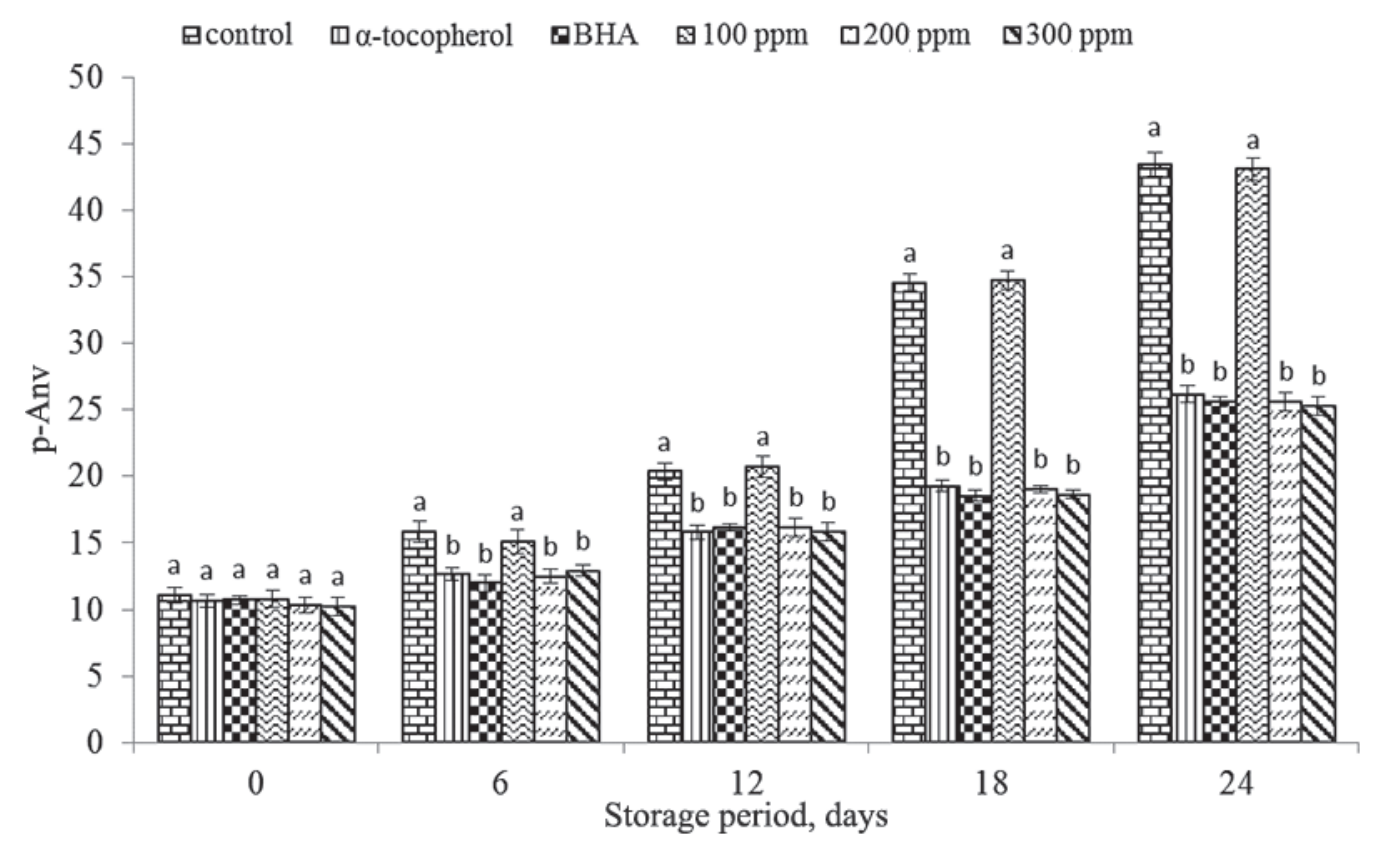

Fig. 2. $p$-Anisidine value ( $p$-AnV) of sunflower oil supplemented with unripe banana peel extracts, BHA and $\alpha$-tocopherol under accelerated storage at $65^{\circ} \mathrm{C}$ for 24 days. Different letters within each storage period denote that they are significantly different $(p<0.05)$ 
Ling, S. S. C., Chang, S. K., Sia, W. C. M., Yim, H. S. (2015). Antioxidant efficacy of unripe banana (Musa acuminata Colla) peel extracts in sunflower oil during accelerated storage. Acta Sci. Pol. Technol. Aliment., 14(4), 343-356. DOI: 10.17306/J.AFS.2015.4.34

Pike, 2010). The $p$-AnV value can be determined by evaluating the absorbance of solution produced from the mixture of oil in isooctane solution with $p$-anisidine $(0.25 \%$ in glacial acetic acid). The added $p$-anisidine reacts with the aldehyde and produces a yellow colored solution. A lower $p$-AnV value indicates a better quality of oil (O'Keefe and Pike, 2010). Figure 2 demonstrated that there were increase of $p$-AnV for all the samples with irregular patterns throughout the storage period. From $6^{\text {th }}$ day onwards, SFO-200, SFO-300, SFO-BHA and SFO-TOCO demonstrated a similar inhibitory effect, of which their $p$-AnV values were $12.49 \pm 0.54,12.89 \pm 0.42,11.99 \pm 0.60$ and $12.63 \pm 0.48$, respectively (Fig. 2). Under accelerated storage for 24 days, the total increase of $p-\mathrm{AnV}$ values were in the following order of SFO (control) $>$ SFO-100 > SFO-TOCO $/$ SFO-BHA $=$ SFO-200/ SFO-300 with the maximum values of $43.42 \pm 0.87$, $43.06 \pm 0.86,26.17 \pm 0.63,25.62 \pm 0.41,25.60 \pm 0.68$ and $25.28 \pm 0.71$, respectively, at $24^{\text {th }}$ day. This indicates that the unripe banana peel extracts is effective in retarding the formation of secondary oxidation products in sunflower oil within 2 years of storage (24 days of accelerated storage condition) at ambient temperature.

Meanwhile after 24 days of storage, by comparing the increase of $p-\mathrm{AnV}$ in SFO-100 with that of SFO200 and SFO-300, SFO-100 demonstrated a higher increase compared to that of SFO-200 and SFO-300 (Fig. 2). This suggests that 200 and $300 \mathrm{ppm}$ of unripe banana peel extracts is sufficient enough to exhibit a protective effect in retarding secondary oxidation of oil. According to the Malaysian Food Act (1983), the maximum safety limit of BHA in food system is $200 \mathrm{ppm}$ (equiv. $1100 \mu \mathrm{M}$ ). Therefore, unripe banana peel could be considered as a good source of natural antioxidant in a food system when compared to the maximum safety limit of BHA. After 24 days of accelerated storage, the control and SFO-100 demonstrated the highest $p$-AnV, demonstrating the higher rate of carbonyl formation compared with SFO-200, SFO-300, BHA and $\alpha$-tocopherol stabilized samples. In another study, Nor et al. (2008) reported that Pandanus amaryllifolius leaf extract $(0.1 \%)$ was demonstrated to be capable of retarding oxidation in palm olein as effectively as the synthetic antioxidant in $p$-AnV test.

\section{Determination of Total Oxidation (ТОTOX Value)}

The total oxidation of the oil sample can be determined based on the calculated $\mathrm{PV}$ and $p$-AnV values. These values are reported as TOTOX value. TOTOX value measures primary and secondary oxidation products, reflecting the initial and later stages of the oil oxidation. Therefore, it provides a better estimation of the progressive oxidative deterioration of the oil (O'Keefe and Pike, 2010). Lower TOTOX value indicates a greater stability of oil sample against oxidative rancidity (Shahidi and Wanasundara, 2002). The TOTOX value of all the samples including the synthetic antioxidants were in the order of SFO-100 $>$ control $>$ SFO-200/SFO-300 $=$ SFO-TOCO $/$ SFO-BHA with maximum values of $180.88 \pm 1.51,179.52$ $\pm 1.25,117.36 \pm 1.64,115.28 \pm 1.21,110.00 \pm 0.78$ and $107.85 \pm 1.13$, respectively (Fig. 3). All the supplemented samples demonstrated positive effects in inhibiting oxidative rancidity except SFO-100. As compared to the control, all the supplemented samples had significantly $(p<0.05)$ lower TOTOX values except SFO-100 (Fig. 3). This could be due to the fact that SFO-100 was not effective in inhibiting oxidative rancidity of sunflower oil. SFO-300 reached a maximum TOTOX value which was higher than the TOTOX value of SFO-BHA. This might due to the fact that unripe banana peel extracts added to sunflower oil did not work as effectively as expected. After 24 days of storage, SFO-100 ppm was observed to be the least effective where it had significantly $(p<0.05)$ higher TOTOX values than $\alpha$-tocopherol and BHA (Fig. 3). The low antioxidant activity of SFO-100 was mainly because of its low efficacy in delaying hydroperoxides formation due to the low concentration of unripe banana peel extract.

\section{lodine Value}

Sunflower oil contains more than $70 \%$ polyunsaturated fatty acids (PUFAs). These PUFAs are highly prone to lipid oxidation (Zhang et al., 2010). During storage, the double bonds of these PUFAs are attacked by free radicals, which results in the formation of conjugated bonds (Kanner et al., 2012). Hence, measuring the amount of unsaturated fatty acids present in sunflower oil can be used as a reference to determine the freshness of the oil (Winne Sia et al., 2014). The freshness of sunflower oil can be determined quantitatively 
Ling, S. S. C., Chang, S. K., Sia, W. C. M., Yim, H. S. (2015). Antioxidant efficacy of unripe banana (Musa acuminata Colla) peel extracts in sunflower oil during accelerated storage. Acta Sci. Pol. Technol. Aliment., 14(4), 343-356. DOI: 10.17306/J.AFS.2015.4.34

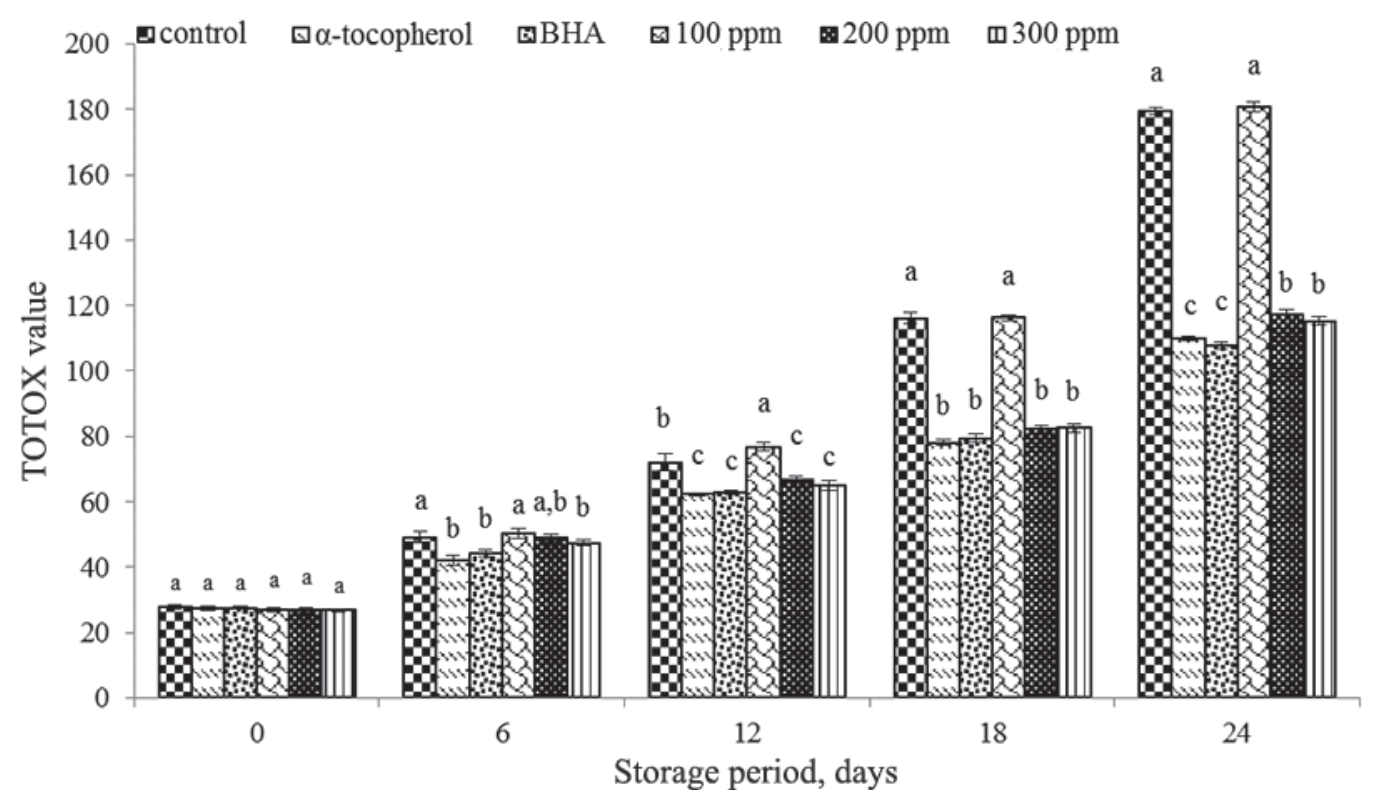

Fig. 3. TOTOX value of sunflower oil supplemented with unripe banana peel extracts, BHA and $\alpha$-tocopherol under accelerated storage at $65^{\circ} \mathrm{C}$ for 24 days. Different letters within each storage period denote that they are significantly different $(p<0.05)$

by adding iodine monochloride to the oil samples. The unsaturated fatty acids react with iodine monochloride to release free iodine. The free iodine can then react with sodium thiosulphate for the determination of iodine value (IV) (O'Keefe and Pike, 2010).

Abdulkarim et al. (2007) reported that the IV indicates the degree of unsaturation of oils. Anwar et al. (2007) and Nor et al. (2008) demonstrated that the IV values greatly reduced with the increase of storage time. The IV values of the stabilized unripe banana peel extract, BHA, $\alpha$-tocopherol and control sunflower oil, over an accelerated storage period of 24 days at $65^{\circ} \mathrm{C}$, was shown in Figure 4. It was observed that the IV value decreases significantly $(p<0.05)$ with the increase time of storage for all samples. The rate of reduction in control was higher than that in sunflower oil containing both synthetic and natural antioxidants. A decreasing IV value of oils is generally attributed to the destruction of the fatty acid double bonds caused by oxidation process. Throughout the 24 days storage period, the total reduction in IV among the samples were in the following order: SFO $($ control $)>$ SFO-100 $>$ SFO-200 $>$ SFO-300 $>$ SFO-TOCO $>$ SFO-BHA (Fig. 4). The untreated sunflower oil sample (control) decreased noticeably throughout 24 days until a minimum value of $91.43 \mathrm{I}_{2} / 100 \mathrm{~g}$. On $0^{\text {th }}$ and $24^{\text {th }}$ day, SFO- 100 demonstrated higher reduction compared to SFO-200 and SFO-300, whereby the IV value of SFO-100 were significantly different $(p<0.05)$ compared to that of the IV values obtained for SFO-200 and SFO-300. On the $12^{\text {th }}$ day, SFO-300, $\alpha$-tocopherol, and BHA demonstrated stronger inhibitory effects against lipid oxidation, while on the $24^{\text {th }}$ day, no significant differences $(p<0.05)$ were noticed between the crude extract at 300 ppm, BHA, and $\alpha$-tocopherol (Fig. 4). As shown in Figure 4, it was clear that both BHA and $\alpha$-tocopherol inhibited oxidation of sunflower oil significantly $(p<0.05)$ as compared to SFO-100 and SFO-200 throughout the storage period. The highest IV of SFO-BHA and SFO-TOCO compared to SFO-100, SFO-200 and SFO-300 at every interval demonstrated the higher efficacies of BHA and $\alpha$-tocopherol to protect the unsaturated bonds of fatty acids in sunflower oil being oxidized by free radicals. From this, it can be deduced that unripe banana peel antioxidant is less effective as the synthetic antioxidants in preventing lipid oxidation. 
Ling, S. S. C., Chang, S. K., Sia, W. C. M., Yim, H. S. (2015). Antioxidant efficacy of unripe banana (Musa acuminata Colla) peel extracts in sunflower oil during accelerated storage. Acta Sci. Pol. Technol. Aliment., 14(4), 343-356. DOI: 10.17306/J.AFS.2015.4.34

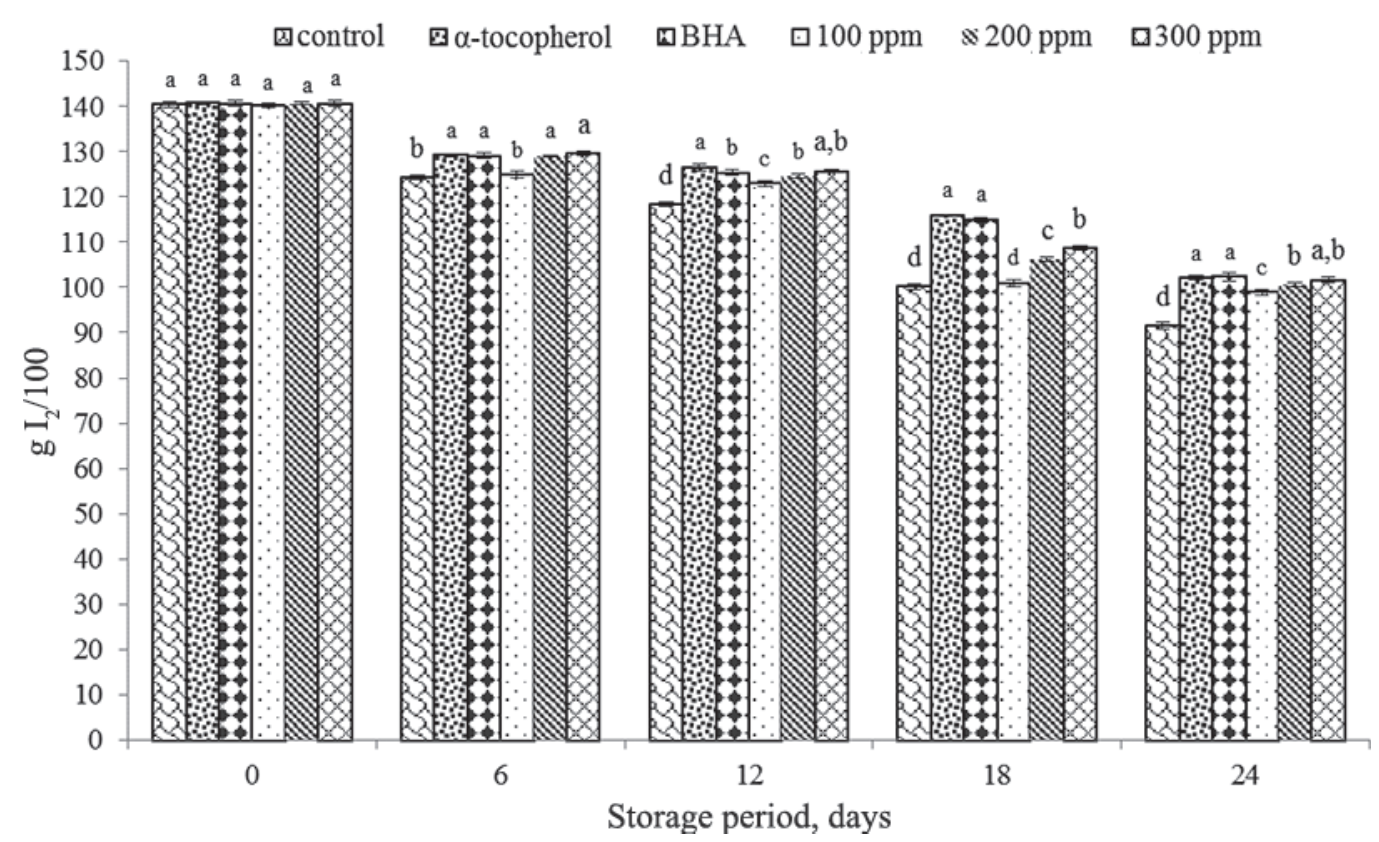

Fig. 4. Iodine value (IV) of sunflower oil supplemented with unripe banana peel extracts, BHA and $\alpha$-tocopherol under accelerated storage at $65^{\circ} \mathrm{C}$ for 24 days. Different letters within each storage period denote that they are significantly different $(p<0.05)$

Thiobarbituric Acid Reactive Substances (TBARS) Thiobarbituric Acid (TBA) is defined as the quantity of malondialdehyde (MDA; mg) presented in $1 \mathrm{~kg}$ of sample (Zhang et al., 2010). MDA is the standard biomarker for measurement of lipid peroxidation of cell membrane despite other biomarkers such as 4-hydroxynonenal and isoprostanes. MDA are generated from the peroxidation of fatty acids with three double bonds and more where it is the most abundant active carbonyl generated from lipid peroxidation in foods containing high amounts of unsaturated fats (Kanner et al., 2012). Thus, MDA is a robust biomarker in terms of measuring lipid peroxidation in vivo. The primary oxidation product, lipid hydroperoxides react with oxygen to form MDA, which contributes to the off-flavour of the oil (Zhang et al., 2010). The MDA levels in an oil sample can be determined through its reaction with thiobarbituric acid (TBA). In this test, MDA reacts with TBA to form TBA-MDA complex which is pink in colour (O'Keefe and Pike, 2010).

Figure 5 depicts the effects of 100, 200 and 300 ppm unripe banana peel extract, BHA, $\alpha$-tocopherol and control on TBARS values of sunflower oil at $65^{\circ} \mathrm{C}$ for 24 days accelerated storage. As shown in Figure 5, regular increase in TBARS value as a function of storage time was observed at all intervals. As the sample concentration increases, the amounts of secondary products detected were lower. This result was in accordance with the obtained $p$-AnV value. This result was also in accordance with the result obtained in the study of garlic extract and pomegranate peel added to sunflower oil, which reported to have stronger protective effects at higher concentrations (Iqbal and Bhanger, 2007). The TBARS values of control in the absence of antioxidant and crude unripe banana peel extract at $100 \mathrm{ppm}$ increase significantly throughout the storage period especially after the $6^{\text {th }}$ day, reaching the maximum value of $0.14 \mathrm{mg} \mathrm{MDA} / \mathrm{mL}$ on $24^{\text {th }}$ day. It was also apparent that the TBARS values of sunflower oil samples stabilized with unripe banana peel extracts and synthetic antioxidants were found to be significantly $(p<0.05)$ lower than the control and SFO-100.

After 24 days of accelerated storage, BHA and $\alpha$-tocopherol managed to show inhibition ability in retarding lipid oxidation with the TBARS value of 0.12 $\pm 0.00 \mathrm{mg} \mathrm{MDA} / \mathrm{mL}$. This indicates that both BHA and 
Ling, S. S. C., Chang, S. K., Sia, W. C. M., Yim, H. S. (2015). Antioxidant efficacy of unripe banana (Musa acuminata Colla) peel extracts in sunflower oil during accelerated storage. Acta Sci. Pol. Technol. Aliment., 14(4), 343-356. DOI: 10.17306/J.AFS.2015.4.34

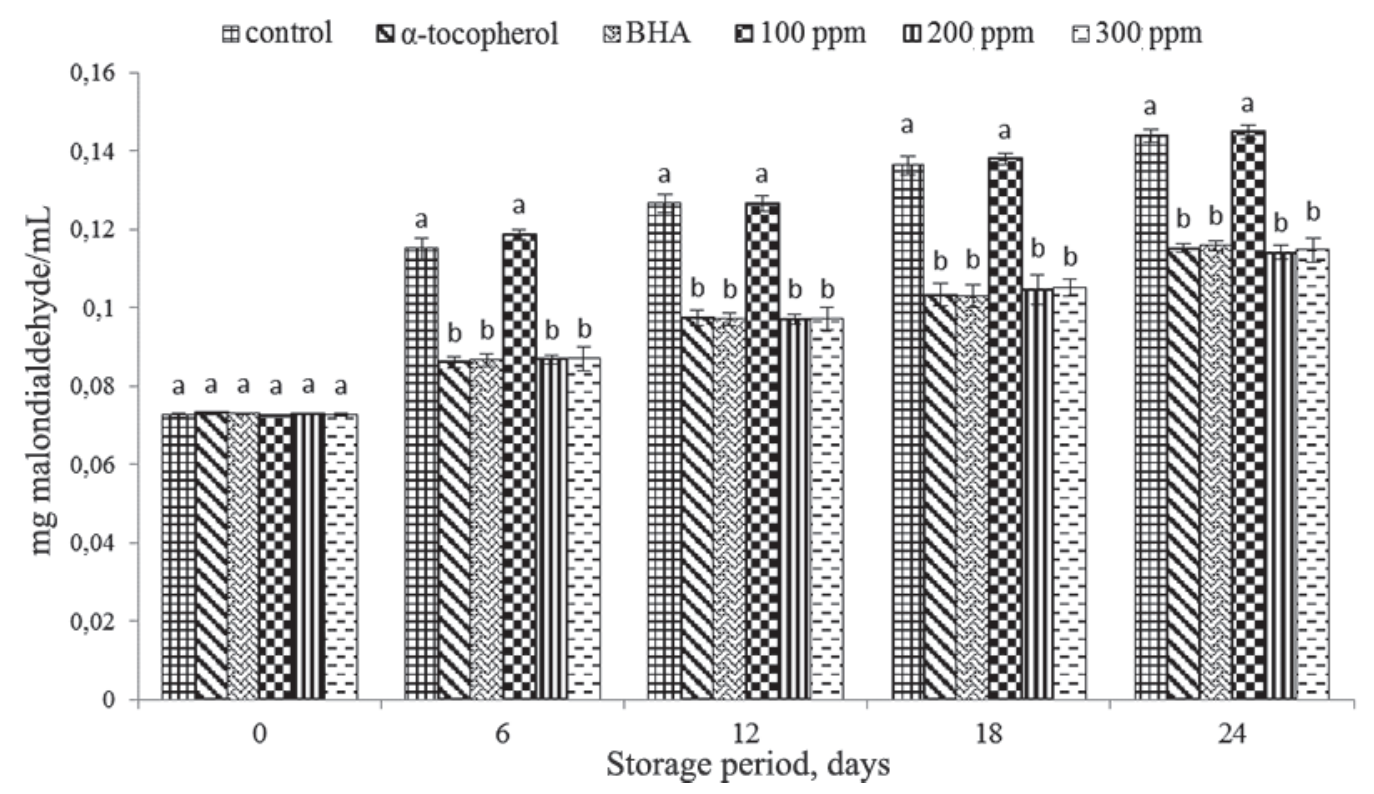

Fig. 5. TBARS value of sunflower oil supplemented with unripe banana peel extracts, BHA and $\alpha$-tocopherol under accelerated storage at $65^{\circ} \mathrm{C}$ for 24 days. Different letters within each storage period denote that they are significantly different $(p<0.05)$

$\alpha$-tocopherol were effective in retarding lipid oxidation. SFO-200 and SFO-300 demonstrated the lowest TBARS values, which was $0.11 \mathrm{mg} \mathrm{MDA} / \mathrm{mL}$ on the $24^{\text {th }}$ day. This shows that both SFO-200 and SFO300 demonstrated a higher antioxidant activity and hence greater protective effect than SFO-100. SFO200, SFO-300, SFO-BHA and SFO-TOCO exhibited comparable inhibitory effects against lipid oxidation as observed on $24^{\text {th }}$ day of the storage duration. This implies that both SFO-200 and SFO-300 are able to prolong the shelf-life of sunflower oil for 2 years at ambient storage by having the antioxidant potency as effective as the allowed BHA concentration of 200 ppm as a food additive. In another study, Monfared et al. (2011) have shown that water and ether extracts of Urtica dioica (stinging nettle) are capable of inhibiting both primary and secondary oxidation of sunflower oil during storage compared to the control, which is in consistent with the results of this study.

\section{Free Fatty Acids (FFA)}

Free fatty acid value is used as an indicator of fat hydrolysis, specifically, the presence of free fatty acids. FFAs are formed due to the hydrolysis of triglycerides and can be promoted by moisture content (O'Keefe and Pike, 2010). The FFA content of SFO (control), SFO-100, SFO-200, SFO-300, SFO-BHA and SFOTOCO during 24 days of accelerated storage were shown in Figure 6. The FFA contents in the sunflower oil demonstrated a gradual increase throughout the storage period. As a comparison among the samples, the total increase of FFA values during the storage period were in the order of SFO (control) $>$ SFO-100 $>$ SFO SFO-200/SFO-300 = SFO-BHA/SFO-TOCO. The antioxidant capacities of SFO-200 and SFO-300 are comparable with $\alpha$-tocopherol and BHA. After 0 day of storage, the FFA values of both control and SFO-100 increased significantly and gradually throughout the storage period until $24^{\text {th }}$ day. Based on the result obtained, it was clear that SFO-200, SFO300, SFO-BHA and SFO-TOCO are able to retard the hydrolysis of triglycerides, thus, preserving sunflower oils for 2 years at room temperature (Fig. 6).

After 24 days of storage time, the untreated sunflower oil sample (control) demonstrated the highest FFA content $(0.38 \pm 0.02 \%)$. Meanwhile, crude extract at $300 \mathrm{ppm}$ demonstrated the lowest FFA content $(0.23 \pm 0.04 \%)$ as shown in Figure 6 . This shows that 
Ling, S. S. C., Chang, S. K., Sia, W. C. M., Yim, H. S. (2015). Antioxidant efficacy of unripe banana (Musa acuminata Colla) peel extracts in sunflower oil during accelerated storage. Acta Sci. Pol. Technol. Aliment., 14(4), 343-356. DOI: 10.17306/J.AFS.2015.4.34

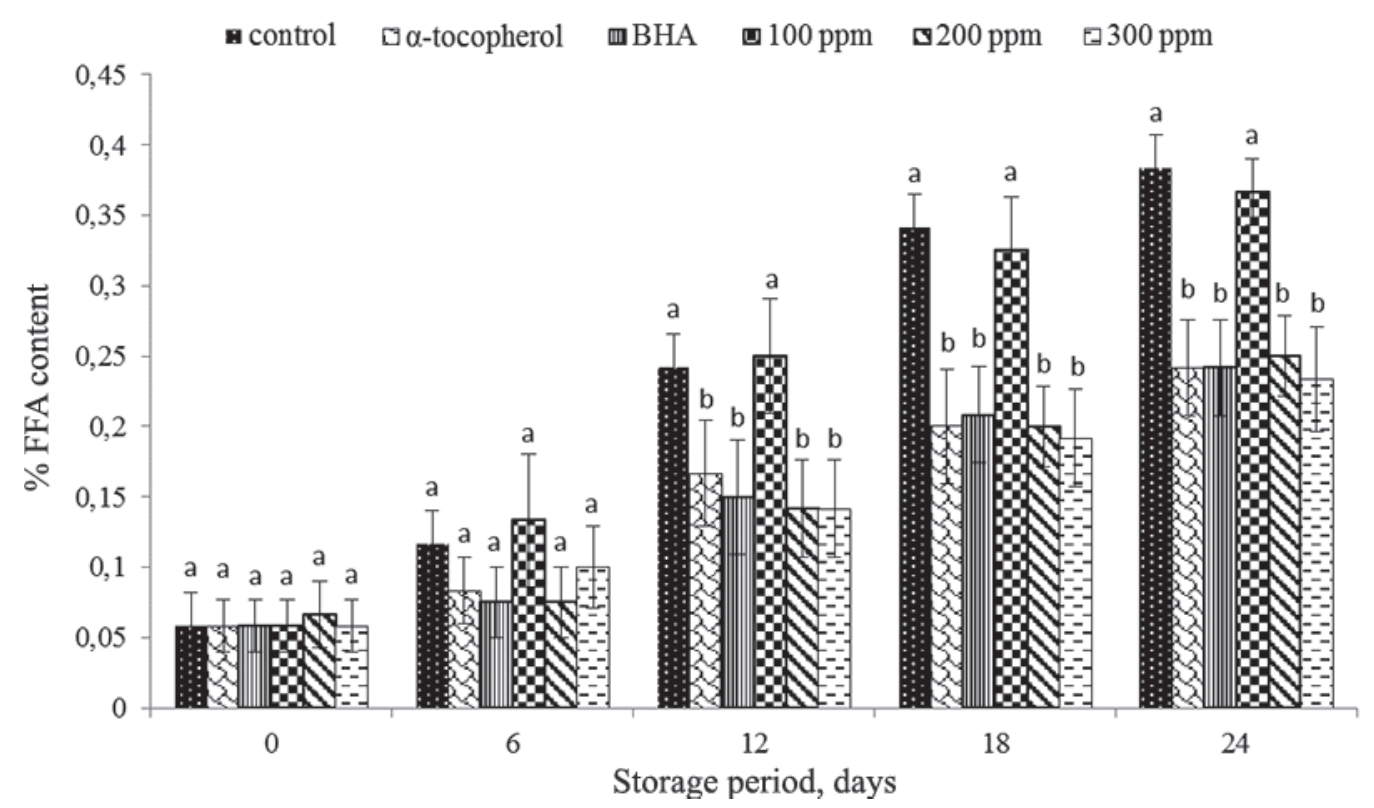

Fig. 6. FFA value of sunflower oil supplemented with unripe banana peel extracts, BHA and $\alpha$-tocopherol under accelerated storage at $65^{\circ} \mathrm{C}$ for 24 days. Different letters within each storage period denote that they are significantly different $(p<0.05)$

all SFO-200, SFO-300, SFO-BHA and SFO-TOCO have the similar inhibitory effect on the lipid oxidation of sunflower oil and are capable of hindering the hydrolysis of triglycerides by extending its shelf-life up to 2 years. Similarly, Iqbal and Bhanger (2007) reported that garlic extract at $1000 \mathrm{ppm}$ is more effective than BHA and BHT at $200 \mathrm{ppm}$ in preventing hydrolysis of triglycerides over longer storage period. Thus, higher concentration of unripe banana peel extracts may be able to give a better protective activity. Future research should be carried out to investigate the effectiveness of unripe banana peel extracts at higher concentrations.

\section{Discussions}

Although it is difficult to stabilize sunflower oil because of its high linoleic acid content, unripe banana peel extract at the concentration of 200 and $300 \mathrm{ppm}$ has been shown to have stabilizing efficacy comparable to synthetic antioxidants such as BHA at its legal limit. Unripe banana peel extract has a strong antioxidative effect during initial and final stages of oxidation under accelerated storage conditions at $65^{\circ} \mathrm{C}$ for 24 days. It improves the resistance of sunflower oil against thermal deteriorative changes. Moreover, polyunsaturated fatty acid content has been saved appreciably by inducing resistance of sunflower oil against oxidative rancidity.

Some studies have demonstrated the effectiveness of other plant extracts in preventing sunflower oil oxidation. For example, carnosic acid from rosemary dried leaves demonstrated strong antioxidant efficacy by protecting sunflower oil from being oxidized (Zhang et al., 2010). Iqbal and Bhanger (2007) investigated the efficacy of garlic extracts and synthetic antioxidants added to sunflower oil. Garlic extract at $1000 \mathrm{ppm}$ demonstrated greater antioxidant efficacy to prevent lipid oxidation compared with synthetic antioxidants. The present study gives an impact for expanding the use of natural antioxidants from fruit wastes, such as banana peel in food industry.

Bananas have a characteristic array of phytochemicals. The phytochemicals that have been reported most in both banana pulp and peel are carotenoids, phenolic compounds and biogenic amines (Oliveira et al., 2008; Pereira and Maraschin, 2015; Tsamo et al., 2015). These phytochemicals have been shown to correlate well with its good antioxidant capacities 
Ling, S. S. C., Chang, S. K., Sia, W. C. M., Yim, H. S. (2015). Antioxidant efficacy of unripe banana (Musa acuminata Colla) peel extracts in sunflower oil during accelerated storage. Acta Sci. Pol. Technol. Aliment., 14(4), 343-356. DOI: 10.17306/J.AFS.2015.4.34

(Bennett et al., 2010; Lim et al., 1997; Sulaiman et al., 2011). However, literature on the phytochemical profiles of the peel and pulp of bananas is still scarce and inconsistent.

Someya et al. (2002) demonstrated that total phenolic content (TPC) was high in banana peels, accounting for $907 \mathrm{mg} / 100 \mathrm{~g}$ of dry weight of sample, where the phenolic compounds identified were mainly epigallocatechin, catechin, and epicatechin. Biogenic amines, such as dopamine have also been identified in banana peel, where the concentration of dopamine in the banana peel was higher than the pulp (Teeranud et al., 2005). There was another study demonstrating that banana peel contains large amounts of catecholamines, dopamine and L-dopamine with significant antioxidant activity (Rafaela et al., 2010). Dopamine have been shown to demonstrate higher antioxidant capacity in vitro [determined using (2,2-diphenyl-1-picrylhydrazyl) DPPH assay] compared to synthetic antioxidants, such as ascorbic acid, reduced glutathione, and some phenolic compounds, such as epigallocatechin gallate (Kanazawa and Sakakibara, 2000).

Kanazawa and Sakakibara (2000) reported that banana peel contain flavonoids, such as naringenin and rutin. Meanwhile, saponin $(24 \mathrm{mg} / \mathrm{g})$ has also been found in Musa sapientum peels (Anhwange, 2008). Unripe banana peel has been shown to contain leucocyanidin, a flavonoid that helps in accelerating the healing of skin wounds as well as surgery wounds (Atzingen et al., 2013). The antioxidative efficacy of unripe banana peel has been shown effective in the prevention and treatment of peptic ulcers in rat model. It is interesting to know that the active agent in unripe bananas is water soluble and becomes inactive in ripe banana peel (Best et al., 1984). More research should be carried out to determine the complete profiles of phytochemicals, such as, phenolic acids, flavonoids, phytoestrogens and carotenoids of bananas (pulp and peel) in relation to their antioxidant capacities or other bioactivities. The combination of these bioactive compounds (phenolic compounds and biogenic amines) might provide synergistic effects to the antioxidant capacity that further enhanced the oxidative stability of oils using unripe banana peel as shown in this study. Considering the potent antioxidant efficacy of unripe banana peel extract, it could be used as food additives for increasing the shelf life of food by preventing lipid peroxidation.

\section{CONCLUSION}

From the present study, it can be concluded that unripe banana peel extract at 200 and $300 \mathrm{ppm}$ has been shown to have strong protective effects against lipid peroxidation of sunflower oil during accelerated storage conditions and demonstrated stabilizing efficacy comparable to commonly used synthetic antioxidants, BHA (200 ppm) at its legal limit. Unripe banana peel extract prolongs the shelf-life of sunflower oil against heat deteriorative changes. Unripe banana peel could be one of the most important sources of natural antioxidants. Therefore, unripe banana peel extract can be recommended as a potent source of antioxidants for the stabilization of food systems, especially unsaturated vegetable oils.

\section{ACKNOWLEDGEMENTS}

The authors wish to thank UCSI University for the financial and laboratory support for this work.

\section{REFERENCES}

Abdulkarim, S. M., Long, K., Lai, O. M., Muhammad, S. K. S., Ghazali, H. M. (2007). Frying quality and stability of high-oleic Moringa oleifera seed oil in comparison with other vegetable oil. Food Chem., 105, 1382-1389.

Aladedunye, F. A., Przybylski, R. (2009). Degradation and nutritional quality changes in oil during frying. J. Am. Oil Chem. Soc., 86, 149-156.

Anhwange, B. A. (2008). Chemical composition of Musa sapientum (banana) peels. J. Food Technol., 6, 263-266.

Anwar, F., Hussain, A. I., Iqbal, S., Bhanger, M. I. (2007). Enhancement of the oxidative stability of some vegetable oils by blending with Moringa oleifera oil. Food Chem., 103, 1181-1191.

Arora, A., Choudhary, D., Agarwal, G., Singh, V. P. (2008). Compositional variation in $\beta$-carotene content, carbohydrate and antioxidant enzymes in selected banana cultivars. Int. J. Food Sci. Technol., 43, 1913-1921.

Atzingen, D. A. N. C., Gragnani, A., Veiga, D. F., Abla, L. E. F., Cardoso, L. L. F., ..., Ricardo, T. (2013). Unripe Musa sapientum peel in the healing of surgical wounds in rats. Acta Cirúrg. Brasil., 28, 33-38. 
Ling, S. S. C., Chang, S. K., Sia, W. C. M., Yim, H. S. (2015). Antioxidant efficacy of unripe banana (Musa acuminata Colla) peel extracts in sunflower oil during accelerated storage. Acta Sci. Pol. Technol. Aliment., 14(4), 343-356. DOI: 10.17306/J.AFS.2015.4.34

Babbar, N., Oberoi, H. S., Uppal, D. S., Patil, R. T. (2011). Total phenolic content and antioxidant capacity of extracts obtained from six important fruit residues. Food Res. Int., 44, 391-396.

Best, R., Lewis, D. A., Nasser, N. (1984). The anti-ulcerogenic activity of the unripe plantain banana (Musa species). Br. J. Pharmacol., 82, 107-116.

Bennett, R. N., Shiga, T. M., Hassimotto, N. M., Rosa, E. A., Lajolo, F. M., Cordenunsi, B. R. (2010). Phenolics and antioxidant properties of fruit pulp and cell wall fractions of postharvest banana (Musa acuminata Juss.) cultivars. J. Agric. Food Chem., 58(13), 7991-8003.

Bhagwat, S., Haytowitz, D. B., Holden, J. M., (ret.). (2014). USDA Database for the Flavonoid Content of Selected Foods, Release 3.1. U.S. Department of Agriculture, Agricultural Research Service, 2014. Retrieved 25 ${ }^{\text {th }}$ March 2015 from Nutrient Data Laboratory Home Page: http:// www.ars.usda.gov/nutrientdata/flav.

Chong, Y. M., Chang, S. K., Sia, W. C. M., Yim, H. S. (2015). Antioxidant efficacy of mangosteen (Garcinia mangostana Linn.) peel extracts in sunflower oil during accelerated storage. Food Biosci., 12, 18-25.

Dillard, C. J., German, J. B. (2000). Phytochemicals: nutrachemicals and human health. J. Sci. Food Agric., 80, 12, 1744-1756.

González-Montelongo, R., Lobo, M. G., González, M. (2010). Antioxidant activity in banana peel extracts: Testing extraction conditions and related bioactive compounds. Food Chem., 119, 1030-1039.

Halliwell, B. (2012). Free radicals and antioxidants: updating a personal view. Nutr. Rev., 70(5), 257-265.

Iqbal, S., Bhanger, M. I. (2007). Stabilization of sunflower oil by garlic extract during accelerated storage. Food Chem., 100, 246-254.

Kanazawa, K., Sakakibara, H. (2000). High content of dopamine, a strong antioxidant, in Cavendish banana. J. Agric. Food Chem., 48, 844-848.

Kanner, J., Gorelik, S., Roman, S., Kohen, R. (2012). Protection by polyphenols of postprandial human plasma and low density lipoprotein modification: the stomach as a bioreactor. J. Agric. Food Chem., 60(36), 8790-8796.

Khan, M. A., Shahidi, F. (2001). Effects of natural and synthetic antioxidants on the oxidative stability of borage and evening primose triacylglycerols. Food Chem., 75, 431-437.

Lim, Y. Y., Lim, T. T., Tee, J. J. (2007). Antioxidant properties of several tropical fruits: A comparative study. Food Chem., 103(3), 1003-1008.

Malheiro, R., Rodrigues, N., Manzke, G., Bento, A., Pereira, J. A., Casal, S. (2013). The use of olive leaves and tea extracts as effective antioxidants against the oxidation of soybean oil under microwave heating. Ind. Crop. Prod., 44, 37-43.

Maqsood, S., Benjakul, S., Abushelaibi, A., Alam, A. (2014). Phenolic compounds and plant phenolic extracts as natural antioxidants in prevention of lipid oxidation in seafood: a detailed review. Compr. Rev. Food Sci. F, 13(6), 1125-1140.

Maqsood, S., Benjakul, S., Shahidi, F. (2013). Emerging role of phenolic compounds as natural food additives in fish and fish products. Crit. Rev. Food Sci. Nutr., 53(2), 162-179.

Monfared, M., Kamkar, A., Khaligh, S. G., Javan, A. J., Asadi, F., Basti A. A. (2011). Antioxidative effects of Iranian Urtica dioica L. extracts on the oxidation of sunflower oil. J. Med. Plants Res., 5(18), 4438-4445.

Normand, L., Eskin, N. A. M., Przybylski, R. (2001). Comparison of the stability of regular and high-oleic sunflower oils. J. Am. Oil Chem. Soc., 84, 331-334.

Nor, F. M., Mohamed, S., Idris, N. A., Ismail, R. (2008). Antioxidative properties of Pandanus amaryllifolius leaf extracts in accelerated oxidation and deep frying studies. Food Chem., 110, 319-327.

Nyam, K. L., Wong, M. M., Long, K., Tan, C. P. (2013). Oxidative stability of sunflower oils supplemented with kenaf seed extract, roselle seed extract and roselle extract, respectively under accelerated storage. Int. Food Res. J., 20(2), 695-701.

O'Keefe, S. F., Pike, O. A. (2010). Fat characterization. In S. S. Nielsen (Ed.), Food analysis (pp. 239-260). New York NY, USA: Springer Science and Business Media.

Okonogi, S., Duangrat, C., Anuchpreeda, S., Tachakittirungrod, S., Chowwanapoonpohn, S. (2007). Comparison of antioxidant capacities and cytotoxicities of certain fruit peels. Food Chem., 103(3), 839-846.

Okuda, S., McClements, D. J., Decker, E. A. (2005). Impact of lipid physical state on the oxidation of methyl linolenate in oil-in water emulsions. J. Agric. Food Chem., 53, 9624-9628.

Oliveira, L., Freire, C. S. R., Silvestre, A. J., Cordero, N. (2008). Lipophilic extracts from banana fruit residues: a source of valuable phytosterols. J. Agric. Food Chem., $56,9520-9525$.

Pazos, M., Gallardo, J. M., Torres, J. L., Medina, I. (2005). Activity of grape polyphenols as inhibitors of the oxidation of fish lipids and frozen fish muscle. Food Chem., 92, 547-557.

Pedraza-Chaverri, J., Cárdenas-Rodríguez, N., Orozco-Ibarra, M., Pérez-Rojas, J. M. (2008). Medicinal properties 
Ling, S. S. C., Chang, S. K., Sia, W. C. M., Yim, H. S. (2015). Antioxidant efficacy of unripe banana (Musa acuminata Colla) peel extracts in sunflower oil during accelerated storage. Acta Sci. Pol. Technol. Aliment., 14(4), 343-356. DOI: 10.17306/J.AFS.2015.4.34

of mangosteen (Garcinia mangostana). Food Chem. Toxicol., 46, 10, 3227-3239.

Pereira, A., Maraschin, M. (2015). Banana (Musa spp.) from peel to pulp: Ethnopharmacology, source of bioactive compounds and its relevance for human health. J. Ethnopharmacol., 160, 149-163.

Perrier, X., De Langhe, E., Donohue, M., Lentfer, C., Vrydaghs, L., ..., Denham, T. (2011). Multidisciplinary perspectives on banana (Musa spp.) domestication. Proc. Natl. Acad. Sci., 108, 11311-11318.

Rafaela, G., Gloria, G. M., Monica, G. (2010). Antioxidant activity in banana peel extracts: Testing extraction conditions and related bioactive compounds. Food Chem., 119(3), 1030-1039.

Ramakrishnan, B., Selvaraj, S., Babu, S., Radhakrishnan, N., Palanisamy, P. (2011). Antioxidant potential of peel extracts of banana varieties (Musa sapientum). Food Nutr. Sci., 2, 1128-1133.

Shahidi, F., Zhong, Y. (2005). Lipid oxidation: measurement methods. In F. Shahidi (Ed.), Bailey's industrial oil and fat products (pp. 357-385). Iowa, USA: John Wiley.

Shahidi, F., Wanasundara, U. N. (2002). Methods for measuring oxidative rancidity in fats and oils. In C. C. Akoh, D. B. Min (Eds.), Food lipids: Chemistry, nutrition and biotechnology (pp. 465-482). New York: Marcel Dekker.

Someya, S., Yoshiki, Y., Okubo, K. (2002). Antioxidant compounds from bananas (Musa cavendish). Food Chem., 79, 351-354.

Sulaiman, S. F., Yusoff, N. A. M., Eldeen, I. M., Seow, E. M., Sajak, A. A. B., Ooi, K. L. (2011). Correlation between total phenolic and mineral contents with antioxidant activity of eight Malaysian bananas (Musa sp.). J. Food Comp. Anal., 24(1), 1-10.

Teeranud, R., Jingtair, R., Yoshinori, U., Kazuhiro, A., Kazuo, C. (2005). Changes in concentrations of phenolic compounds and polyphenol oxidase activity in banana peel during storage. Food Preserv. Sci., 31, 111-115.

Tsamo, C. V. P., Herent, M. F., Tomekpe, K., Emaga, T. H., Quetin-Leclercq, J., ..., Andre, C. (2015). Phenolic profiling in the pulp and peel of nine plantain cultivars (Musa sp.). Food Chem., 167, 197-204.

US Department of Agriculture (USDA) (2014). USDA National Nutrient Database for Standard Reference, Release 27. Retrieved February 7, 2015, from http://www. nal.usda.gov/fnic/foodcomp/search/

Valmayor, R. V., Jamaluddin, S. H., Silayoi, B., Kusumo, S., Danh, L. D., Pascua, O. C., Espino, R. R. C. (2002). Banana cultivars names and synonyms in Southeast Asia. Los Baños, Philippines: INIBAP Regional Office for Asia and the Pacific.

Winne Sia, C. M., Ismail, A., Mohd, E. N., Akowuah, G. A., Ho, C. W., Yim, H. S. (2014). The effectiveness of rambutan (Nephelium lappaceum L.) extract in stabilization of sunflower oil under accelerated conditions. Antioxidants, 3, 371-386.

Yim, H. S., Chye, F. Y., Liow, M. L., Ho, C. W. (2013). Antioxidant potential of Pleurotus Porringens extract and application in sunflower oil during accelerated storage. Chiang Mai J. Sci., 40(1), 34-48.

Zhang, Y., Yang, L., Chen, X., Wang, F., Liu, F. (2010). Oxidative stability of sunflower oil supplemented with carnosic acid compared with synthetic antioxidant during accelerated storage. Food Chem., 118, 656-662.

Accepted for print - Zaakceptowano do druku: 25.08.2015

Received - Przyjęto: 30.05.2015

For citation - Do cytowania

Ling, S. S. C., Chang, S. K., Sia, W. C. M., Yim, H. S. (2015). Antioxidant efficacy of unripe banana (Musa acuminata Colla) peel extracts in sunflower oil during accelerated storage. Acta Sci. Pol. Technol. Aliment., 14(4), 343-356. DOI: 10.17306/J.AFS.2015.4.34 